\title{
www.czasopisma.pan.pl \\ The Influence of Sand Grains Properties on Electrical Properties of Moulding Sand with Inorganic Binder
}

\author{
B. Opyd *, K. Granat \\ Wroclaw University of Technology, Department of Foundry Engineering, Plastics and Automation, \\ Smoluchowskiego 25, 50-372 Wrocław, Poland \\ *Corresponding author. E-mail address: beata.opyd@pwr.edu.pl
}

Received 11.05.2015; accepted in revised form 29.05.2015

\begin{abstract}
The paper presents the results of basic research on the influence of the properties of sand grains on electrical properties of water glass moulding sands. It shows electrical properties of the main component - sand grains, crucial to the kinetics of moulding sands heating, such as permittivity $\varepsilon \mathrm{r}$ and loss factor tg. Measurements were carried out with the use of the perturbation method for silica, chromite and olivine sands of different mineral, chemical composition and particle size distribution, as well as for moulding sands with water glass grade 145. Analysis of the results of measurements of electrical properties shows that all moulding sands are characterized by a similar permittivity $\varepsilon_{\mathrm{r}}$ and loss factor tg $\delta$. It was found that the electrical properties and the quantity and quality of other components may have a decisive influence on the effectiveness and efficiency of the microwave heating of moulding sands with sand grains. In determining the ability to efficiently absorb the microwave radiation for mixtures which moulding sands are, the impact of all components influencing their individual technological parameters should be taken into account.
\end{abstract}

Keywords: Innovative foundry technologies and materials, Microwaves, Moulding sand, Sand grains, Water glass

\section{Introduction}

The use of microwave radiation for drying or hardening mould and core made from moulding sands with inorganic binder, in particular with water glass and biodegradable binder, is gaining popularity as it allows to obtain measurable benefits in terms of shortening the process time and reducing the addition of binding material. [1-3].

The power dispersed in the material heated by microwave depends among other things on the magnitude and frequency of the electromagnetic field and the relative permittivity $\varepsilon_{\mathrm{r}}$ and the loss factor tg $\delta$ of this material [4]. To assess the possibility of using microwave heating process in foundry processes it is therefore necessary to define the electrical properties of both the moulding sands as well as their individual components, because they determine the effectiveness and efficiency of microwaveassisted production of foundry moulds and cores. [4-6].

Among the many factors determining the selection of qualitative and quantitative components of moulding sand the various techniques of foundry moulds and cores can be distinguished [7]. Moulding sands exposed to microwave field will be heated in a different way, what is determined by their chemical, mineralogy, quantitative and qualitative composition [5-6]. The research presented here is focused on gaining basic knowledge on kinetics of heating in a microwave moulding and core sands, prepared with using a various types of sand grains, by identifying their basic electrical properties. As a result, in the 
future, thanks to the mathematical model of the process of microwave heating of foundry materials it will be possible to obtain finished castings of suitable quality using disposable moulds and cores dried and hardened using microwave energy.

\section{Idea and methodology of the research}

\subsection{Materials}

On the basis of recognition of the literature [7] and my own experiences to study the electrical properties of the sand grains in moulding sands, three commercially available types of moulding sands were selected: silica, chromite and olivine of similar, comparable composition of particle size distribution. The basic properties, important in the context of their use in the microwave field are summarized in Table 1. Grains surface topography of the individual moulding sands is presented in Figure 1.

In this research the designations of moulding sands selected for testing and intended to be used for the microwave heated matrix of water glass moulding sands were used according to grain size, based on the numbers of sieves, which gathered main fraction obtained from the sieve analysis.

Table 1

Selected properties of sand grains used in the research

\begin{tabular}{|c|c|c|c|}
\hline Designation & Moulding sand & $\begin{array}{l}\text { Density } \\
{\left[\mathrm{kg} / \mathrm{m}^{3}\right]}\end{array}$ & Chemical analysis \\
\hline $\mathrm{K} 1$ & $\begin{array}{l}\text { Silica sand } \\
0.20 / 0.16 / 0.10\end{array}$ & \multirow{2}{*}{2650} & \multirow{2}{*}{$\begin{array}{l}\mathrm{SiO}_{2}-99.25 \% \\
\mathrm{Fe}_{2} \mathrm{O}_{3}-0.07 \%\end{array}$} \\
\hline $\mathrm{K} 2$ & $\begin{array}{l}\text { Silica sand } \\
0.20 / 0.315 / 0.16\end{array}$ & & \\
\hline $\mathrm{C} 1$ & $\begin{array}{l}\text { Chromite sand } \\
0.20 / 0.315 / 0.16\end{array}$ & \multirow{2}{*}{4500} & \multirow{2}{*}{$\begin{array}{l}\mathrm{Cr}_{2} \mathrm{O}_{3}-46.12 \%, \\
\mathrm{Al}_{2} \mathrm{O}_{3}-14.15 \%, \\
\mathrm{Fe}_{2} \mathrm{O}_{3}-28.87 \% \\
\mathrm{MgO}-9.67 \% \\
\mathrm{SiO}_{2}-0.4 \%\end{array}$} \\
\hline $\mathrm{C} 2$ & $\begin{array}{l}\text { Chromite sand } \\
0.20 / 0.315 / 0.40\end{array}$ & & \\
\hline $\mathrm{O} 1$ & $\begin{array}{l}\text { Olivine sand } \\
0.20 / 0.315 / 0.16\end{array}$ & \multirow{2}{*}{3300} & \multirow{2}{*}{$\begin{array}{l}\mathrm{MgO}-48 . \%, \\
\mathrm{SiO}_{2}-41.0 \% \\
\mathrm{Fe}_{2} \mathrm{O}_{3}-7.0 \%\end{array}$} \\
\hline $\mathrm{O} 2$ & $\begin{array}{l}\text { Olivine sand } \\
0.20 / 0.315 / 0.40\end{array}$ & & \\
\hline
\end{tabular}

For the measurement of electrical properties of the moulding sand with an inorganic binder, depending on the type of matrix used, based on the primary literature $[1,7]$ water glass 145 was selected with a molar modulus $\mathrm{SiO}_{2} / \mathrm{Na}_{2} \mathrm{O}$ of $2.4 \div 2.6$.

Moulding sands of selected sand grains was prepared using the addition of 5 parts by weight of water glass with 95 parts by weight of sand. The moulding sands were prepared in a paddle mixer, and then roller fittings were concentrated with a device for vibration compaction of samples.
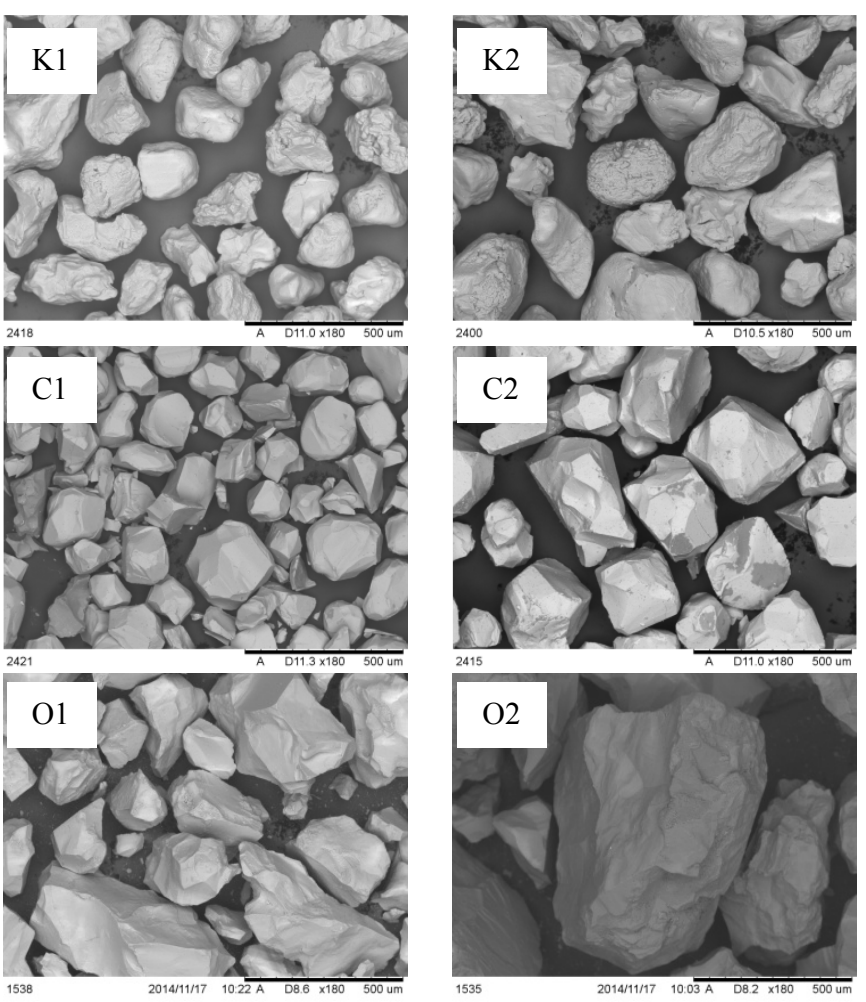

Fig. 1. Grains surface topography of sand grains used in the research. SEM

\subsection{Scope and methodology of the research}

The behaviour of the materials in the alternating electric field is described by two main parameters. The first is the relative permittivity $\varepsilon_{\mathrm{r}}$, which describes how the material is polarized in an electric field. The second parameter is a loss factor (loss tangent $\operatorname{tg} \delta)$, which determines how much of the energy is converted into heat in the material subjected to microwave radiation. At constant intensity and frequency of the microwave field, the product of these properties allows to rank the materials in terms of efficiency of absorbing microwave radiation [4-5].

In order to determine the electrical properties by the perturbation method, at a frequency of $2.45 \mathrm{GHz}$, the granular material which is silica, chromite and olivine water glass moulding sands, the position of the waveguide resonant cavity was applied, as described in [8].

Measurements of electrical properties was carried out at temperature of $20^{\circ} \mathrm{C}$ and the relative humidity of $40 \%$ on the three samples of sand grains and moulding sands made on their matrix. Moulding sands have been previously dried at temperature of $105^{\circ} \mathrm{C}$. 


\section{Results}

In Table 2 and in Figures 2-3 there are summarized the average values of measurements of permittivity $\varepsilon_{\mathrm{r}}$ and loss factor $\operatorname{tg} \delta$ of selected types of sand grains and water glass moulding sands.

Table 2.

Summary of the results of electrical properties measurements of sand grains and moulding compounds of $5 \%$ by weight of water glass grade 145 (described in text)

\begin{tabular}{lccc}
\hline Designation & $\begin{array}{c}\text { Average } \\
\text { Permittivity } \varepsilon_{1}\end{array}$ & $\begin{array}{c}\text { Average loss } \\
\text { factor } \operatorname{tg} \delta\end{array}$ & $\begin{array}{c}\text { Product } \\
\varepsilon_{\mathrm{r}} * \operatorname{tg} \delta\end{array}$ \\
\hline $\mathrm{K} 1$ & 2.18 & 0.0009 & 0.0020 \\
\hline $\mathrm{MK} 1$ & 1.88 & 0.0366 & 0.0690 \\
\hline $\mathrm{S}_{\mathrm{K} 1}$ & 0.86 & 40.64 & 34.50 \\
\hline $\mathrm{K} 2$ & 2.21 & 0.0015 & 0.0033 \\
\hline $\mathrm{MK} 2$ & 1.94 & 0.0415 & 0.0810 \\
\hline $\mathrm{S}_{\mathrm{K} 2}$ & 0.88 & 27.67 & 24.55 \\
\hline $\mathrm{C} 1$ & 3.02 & 0.0012 & 0.0036 \\
\hline $\mathrm{MC} 1$ & 2.45 & 0.0275 & 0.0670 \\
\hline $\mathrm{S}_{\mathrm{C} 1}$ & 0.81 & 22.91 & 18.61 \\
\hline $\mathrm{C} 2$ & 3.04 & 0.0017 & 0.0052 \\
\hline $\mathrm{MC} 2$ & 2.46 & 0.0271 & 0.0670 \\
\hline $\mathrm{S}_{\mathrm{C} 2}$ & 0.81 & 15.94 & 12.88 \\
\hline $\mathrm{O} 1$ & 2.43 & 0.0022 & 0.0053 \\
\hline $\mathrm{MO} 1$ & 2.16 & 0.0403 & 0.0870 \\
\hline $\mathrm{S}_{\mathrm{O} 1}$ & 0.89 & 18.33 & 16.42 \\
\hline $\mathrm{O} 2$ & 2.45 & 0.0024 & 0.0059 \\
\hline $\mathrm{MO} 2$ & 2.23 & 0.0385 & 0.0860 \\
\hline $\mathrm{S}_{\mathrm{O} 2}$ & 0.91 & 16.05 & 14.58 \\
\hline
\end{tabular}

Analysis of measurements results of electrical permittivity $\varepsilon_{\mathrm{r}}$ proves that all sand grains exposed to microwave field have a relatively large capacity for polarization. The lowest value of permittivity has a silica sand $\mathrm{K} 1\left(\varepsilon_{\mathrm{r}}=2.18\right)$. whereas the largest a chromite sand $\mathrm{C} 2\left(\varepsilon_{\mathrm{r}}=3.04\right)$. It has been observed that these results are similar for different types of moulding sands. differing only in particle size distribution.

Permittivity of moulding sands. prepared with selected sand grains ranges from 1.88 to moulding sand with silica sand MK1 to 2.46 for the moulding sand with chromite sand MC2.

Moulding sands prepared on the matrix of one species of sand. but of different composition of particle size distribution. exhibit similar values for both of permittivity and loss factor.

Analysis of the measurements results of the loss factor leads to the conclusion that all tested sands species are characterized by low loss and therefore low susceptibility to absorb the energy of the microwave field. It is confirmed by the value of the product of the permittivity and loss factor (from 0.002 for silica sand $\mathrm{K} 1$ and to 0.0059 for olivine sand $\mathrm{O} 2$ ).

Determination of the loss factor for water glass moulding sands indicates a relatively high susceptibility of moulding sands to the microwave field. It was found based on the value of the product of permittivity and loss factor of selected moulding sands that among all tested samples. in comparison to other tested moulding sands. the moulding sands on the matrix of silica sand
MK2. olivine sand MO1 and olivine sand MO2 will heat up most effectively.

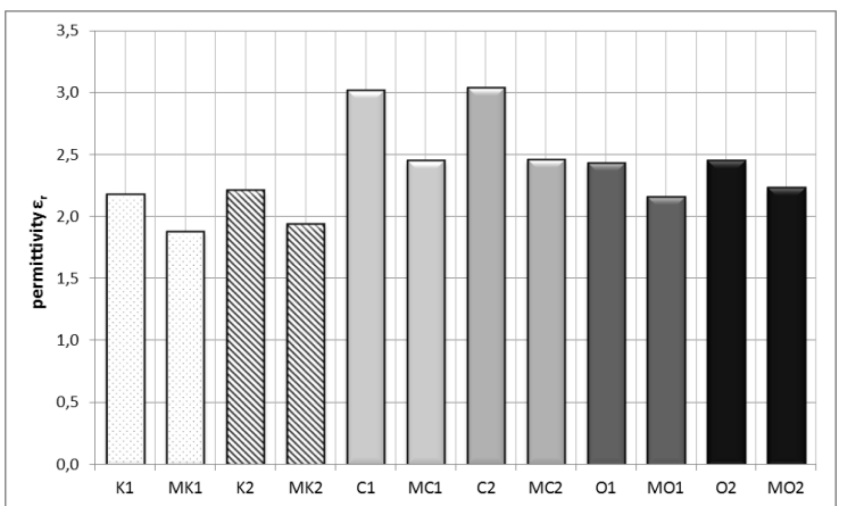

Fig. 2. Permittivity value of various types of sand grains and moulding sands with water glass 145

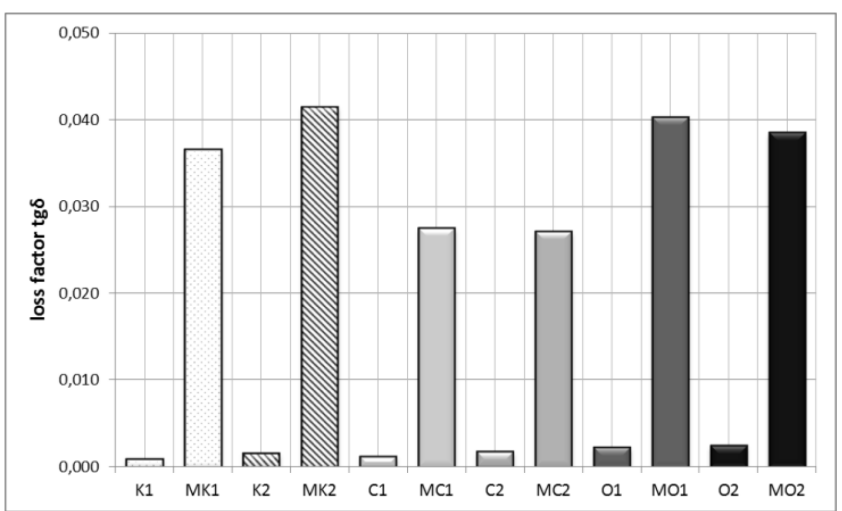

Fig. 3. Loss factor value of various types of sands grains and moulding sands with water glass 145

The measurement results of permittivity $\varepsilon_{\mathrm{r}}$ of moulding sands made of selected species of matrix demonstrate that the combination of sand grain with water glass reduces the value of this parameter compared to the specified parameter for the particular matrix. These changes are expressed as the ratio of the electrical properties of the the moulding sands to the electrical properties of the sand indicated by the symbol $\mathrm{S}$ in Table 2 . The ratio value of each of the analysed cases amounts an average of about 0.85 . As a result. moulding sands will be more effectively polarized in the microwave field with a frequency of $2.45 \mathrm{GHz}$.

In the case of loss factor $\operatorname{tg} \delta$ this effect is the opposite. the value specified for matrix grain is many times lower than for the moulding sands made on their matrix. The biggest difference in the value of the loss factor of moulding sand and matrix grain was noted for silica sand K1 of the main fraction of $0.20 / 0.16 / 0.10$. Then the value of moulding sand loss factor stemming from its matrix is 40 times higher than that specified for the sand. Among all tested types of sand grains the smallest differences in $\operatorname{tg} \delta$ values were observed in the case of moulding sand on the matrix of the chromite sand MC2. The effectiveness of heating the water glass moulding sands is several times higher than heating only the sand grains. 


\section{Conclusions}

In studies on the effect of properties used in research of the sand grain types on electric parameters of moulding sands with the inorganic binder. it was found that:

- determination of permittivity $\varepsilon_{\mathrm{r}}$ and the loss factor $\operatorname{tg} \delta$ of matrix grains allows for optimal selection of components of water glass moulding sands for microwave heating,

- $\quad$ all of the tested matrix grains did not show susceptibility to absorb energy of microwave field with a frequency of $2.45 \mathrm{GHz}$,

- moulding sands produced with the use of certain types of matrix exhibit a relatively high capacity for heating in a microwave field. which results from the presence of water glass in it,

- the value of permittivity and loss factor of the water glass moulding sands are dependent on the species and the mineralogical composition of the sand,

- moulds and cores made of the water glass moulding sand on the olivine sand matrix. heated by microwaves with frequency at $2.45 \mathrm{GHz}$. are more susceptible to effective hardening than the moulding sands on silica sand or the chromite sand matrix,

- $\quad$ in order to determine the electrical properties of mixtures such as moulding sands. the impact of all components influencing their individual technological parameters must be taken into account,

- $\quad$ in further research. the impact of the species quantity of water glass to the effectiveness and efficiency of moulding sand heating intended for microwave heating will be specified.

\section{Acknowledgements}

The project was financed from the funds of the National Science Centre (Poland) granted on basis of the decision number DEC2013/11/N/ST 8/00214.

\section{References}

[1] Stachowicz, M., Granat, K. \& Nowak, D. (2011). Application of microwaves for innovative hardening of environment-friendly water-glass moulding sands used in manufacture of cast-steel castings. Archives of Civil and Mechanical Engineering. 11(1), 209-219. DOI: 10.1016/ S1644-9665(12)60184-8.

[2] Grabowska, B. \& Holtzer, M. (2007). Application of microwave radiation for crosslinking of sodium polyacrylate/silica gel system used as a binder in foundry sands. Polimery. 52(11/12), 841-847. ISSN: (0032-2725). (in Polish).

[3] Wang, J., Zitian, F., Xiaolei, Z. \& Di, P. (2009). Properies of sodium silicate bonded sand hardened by microwave heating. China Foundry. 6(3), 191-196. ISSN 1672-6421.

[4] Ashby, M., Shercliff, D. \& Cebon, H. (2011). Materials Engineering. vol. 2. Łódź: Publishing House Galaktyka Sp. $\mathrm{z}$ o. o. (in Polish).

[5] Mujumdar, S.A. (Ed.) (1995). Handbook of Industrial Drying . New York: Marcel Decker.

[6] Kowalski, S.J., Rajewska, K., Rybicki, A. (2005). Physical basics of microwave drying. Poznań: Editorial Office of Poznan University of Technology. (in Polish).

[7] Lewandowski, L. (1997). Materials for molds. Kraków: Akapit. (in Polish).

[8] Granat, K., Opyd, B., Stachowicz, M., Nowak, D. \& Jaworski, G. (2013). Usefulness of foundry tooling materials in microwave heating process. Archives of Metallurgy and Materials. 58(3), 919-922. DOI: 10.2478 /amm-2013-0101. 